\title{
The difference between trivial and scientific names: There were never any true cheetahs in North America
}

\author{
S. Faurby ${ }^{1,2^{*}}$, L. Werdelin ${ }^{3}$ and J. C. Svenning ${ }^{4}$
}

\begin{abstract}
Dobrynin et al. (Genome Biol 16:277, 2015) recently published the complete genome of the cheetah (Acinonyx jubatus) and provided an exhaustive set of analyses supporting the famously low genetic variation in the species, known for several decades. Their genetic analyses represent state-of-the-art and we do not criticize them. However, their interpretation of the results is inconsistent with current knowledge of cheetah evolution. Dobrynin et al. suggest that the causes of the two inferred bottlenecks at 100,000 and 10,000 years ago were immigration by cheetahs from North America and end-Pleistocene megafauna extinction, respectively, but the first explanation is impossible and the second implausible.
\end{abstract}

\section{Correspondence}

Dobrynin et al. [1] appear to take the common name of the extinct North American cat Miracinonyx, which often is called the "American cheetah" to mean that the species is a close relative of the true cheetah, even though they correctly cite that ancient DNA shows Miracinonyx spp. nested within the genus Puma [2]. This is based on a single mitochondrial marker and could represent mitochondrial capture masking a true relationship between Miracinonyx and Acinonyx, but this molecular result was taken by its authors as support of prior morphological analysis showing that many of the specifically "cheetah-like" adaptations of Miracinonyx are convergences due to similar life styles [3]. No fossils of Acinonyx are known from North America, despite the extensive fossil record from the continent, while no fossils of Miracinonyx are known outside North America. Finally, both Acinonyx and Miracinonyx originated more than two million years ago [3] so that even if Acinonyx and Miracinonyx were sister genera, Miracinonyx would still not affect the population dynamics of Late Pleistocene Acinonyx. Thus, North American species

\footnotetext{
* Correspondence: faurby@mncn.csic.es

${ }^{1}$ Section of Biology and Environmental Science, Department of Chemistry and Bioscience, Aalborg University, 9220 Aalborg, Øst, Denmark

${ }^{2}$ Department of Biogeography and Global Change, Museo Nacional de Ciencias Naturales, CSIC, Calle José Gutiérrez Abascal 2, 28006 Madrid, Spain Full list of author information is available at the end of the article
}

are irrelevant to explaining the results obtained by Dobrynin et al.

The interpretation by Dobrynin et al. for the second bottleneck, though not impossible, is also unlikely. The authors apparently suppose that megafaunal extinction occurred 10-12,000 years BP globally but all the examples of extinctions they mention are North American, a continent which, as we already discussed, never had any true cheetahs. Extinctions in Africa, which are much more relevant to cheetahs, are more prolonged and go back to the early Pleistocene [4]. We note also that the natural range of Acinonyx includes some of the areas of the world with the smallest Late Pleistocene megafauna extinctions [5]. Hence, tying the inferred population bottleneck to megafauna extinction seems problematic in an African context.

Dobrynin et al. used two methods to infer population history: $\mathrm{DaDi}$ software and the pairwise sequentially Markovian coalescent (PSMC) model. Only DaDi inferred two bottlenecks, whereas PSMC indicated continuous population decline. They suggest that the differences are because the power of PSMC is inadequate to infer the bottlenecks but they do not appear to have tested the preferred model of PSMC (of a gradual consistent decline) in $\mathrm{DaDi}$, making it difficult to compare the two methods. We also caution about the precision of the estimated dates. Johnson et al. [6] estimate the divergence time between 
Felis and Acinonyx to 6.7 million years ago, which is close to the estimate of 7 million years ago used by Dobrynin et al., but Johnson et al [6] give a confidence interval of 5.39.2 million years. Generation times are equally tricky. Dobrynin et al. use 3 years, which is intermediate between the age of first reproduction of 2 years and the average generation interval of 5.3 years estimated by Kelly [7]. Combining these uncertainties, we cannot be sure if the inferred events are actually twice or half as old as reported.

We think that the simplest explanation of the patterns may be a gradual decline in Acinonyx as inferred by the PSMC algorithm, potentially with sharper declines in some periods as suggested by the $\mathrm{DaDi}$ analysis. Homo sapiens first appeared 200,000 years ago [8] and significant advances in the culture and technology of this species took place in the subsequent 100,000 years, both in South and central Africa $[9,10]$ (no data are available for eastern Africa). This may suggest a role for $H$. sapiens in the population dynamics of cheetahs, most likely as a consequence of interference competition. Such a process has been suggested for early Pleistocene large carnivore extinctions in Africa, potentially as a consequence of interactions with early Homo [4].

In conclusion, we find that the hypotheses of Dobrynin et al. to explain the inferred population bottlenecks of cheetahs lack support from either molecular systematics, paleontology, or the history of the African mammal fauna. We suggest a possible alternative scenario based on the events in Africa during the past 200,000 years, a scenario that requires further testing but that is plausible given available knowledge.

\section{Competing interests}

The authors declare that they have no competing interests.

\section{Authors' contributions}

SF led the writing of the paper with input from LW and JCS. All authors read and approved the final manuscript.

\section{Author details}

${ }^{1}$ Section of Biology and Environmental Science, Department of Chemistry and Bioscience, Aalborg University, 9220 Aalborg, Øst, Denmark.

${ }^{2}$ Department of Biogeography and Global Change, Museo Nacional de Ciencias Naturales, CSIC, Calle José Gutiérrez Abascal 2, 28006 Madrid, Spain. ${ }^{3}$ Swedish Museum of Natural History, Department of Palaeobiology, Box 50007, 10405 Stockholm, Sweden. ${ }^{4}$ Section for Ecoinformatics \& Biodiversity, Department of Bioscience, Aarhus University, Ny Munkegade 114, 8000 Aarhus C, Denmark.

Received: 23 December 2015 Accepted: 11 April 2016

Published online: 05 May 2016

\section{References}

1. Dobrynin P, Liu S, Tamazian G, Xiong Z, Yurchenko AA, Krasheninnikova K. Genomic legacy of the African cheetah, Acinonyx jubatus. Genome Biol. 2015;16:277

2. Barnett R, Barnes I, Phillips MJ, Martin LD, Harington CR, Leonard JA, et al. Evolution of the extinct sabretooths and the American cheetah-like cat. Curr Biol. 2005;15:R589-90.
3. Van Valkenburgh B, Grady F, Kurtén B. The Plio-Pleistocene cheetah-like cat Miracinonyx inexpectatus of North America. J Vert Paleontol. 1990;10:434-54

4. Werdelin L, Lewis ME. Temporal change in functional richness and evenness in the eastern African Plio-Pleistocene carnivoran guild. PLoS One. 2013;8:e57944.

5. Sandom C, Faurby S, Sandel B, Svenning JC. Global late Quaternary megafauna extinctions linked to humans, not climate change. Proc R Soc B. 2014;281:20133254.

6. Johnson WE, Eizirik E, Pecon-Slattery J, Murphy WJ, Antunes A, Teeling E, et al. The Late Miocene radiation of modern Felidae: a genetic assessment. Science. 2006;311:73-7.

7. Kelly MJ. Lineage loss in Serengeti cheetahs: consequences of high reproductive variance and heritability of fitness on effective population size. Conserv Biol. 1999;15:137-47.

8. McDougall I, Brown FH, Fleagle JG. Stratigraphic placement and age of modern humans from Kibish, Ethiopia. Nature. 2005;433:733-6.

9. Marean CW. Pinnacle Point Cave 13B (Western Cape Province, South Africa) in context: the Cape floral kingdom, shellfish, and modern human origins. J Hum Evol. 2010;59:425-43.

10. Yellen JE, Brooks AS, Cornelissen E, MehIman MJ, Stewart K. A Middle Stone Age worked bone industry from Katanda, Upper Semliki Valley, Zaire. Science. 1995:268:553-6.
Submit your next manuscript to BioMed Central and we will help you at every step:

- We accept pre-submission inquiries

- Our selector tool helps you to find the most relevant journal

- We provide round the clock customer support

- Convenient online submission

- Thorough peer review

- Inclusion in PubMed and all major indexing services

- Maximum visibility for your research

Submit your manuscript at www.biomedcentral.com/submit
Biomed Central 